Open Academic Journal of Advanced Science and Technology

ISSN 2577-7807

Vol. 3, No. 1, pp. 6-10

2019

DOI: $10.33094 / 5.2017 .2019 .31 .6 .10$

(C) 2019 by the authors; licensee Online Academic Press, USA

\title{
A Microstrip Monopole Antenna with C-shaped Patch for Multiband Applications
}

Ruaa Shallal Abbas Anooz ${ }^{1}$

\author{
'Avionics Technical Eng. Dpt., \\ Technical Engineering College / Al- \\ Furat Al-Awsat Technical University, \\ Iraq. \\ Email:ruaaok_2009@yahoo.com \\ Licensed: \\ This work is licensed under a Creative \\ Commons Attribution 4.0 License. \\ Keywords: \\ Monopole antenna \\ Microstrip antenna \\ Multiband Antenna. \\ Accepted: 9 May 2019 \\ Published: 22 May 2019
}

\begin{abstract}
In this study, a monopole antenna based on C-shaped microstrip patch for multiband applications has been presented. The projected antenna uses FR-4 substrate and reduced ground plane (defected ground plane) with a compact size of $14 \mathrm{~mm} \times 24 \mathrm{~mm}$. Reception tools parameters have been encoded and inserted by means of CST electromagnetic software package. The simulation consequences of the proposed antenna in terms of $S 11$ responses, gain and radiation patterns are appropriate for Wi MAX, C-band, and WLAN applications for recent communication systems.
\end{abstract}

Funding: This study received no specific financial support.

Competing Interests: The author declares that there are no conflicts of interests regarding the publication of this paper.

\section{Introduction}

In the past few years, the demand for multi-band antennas has increased as a result of the rapid development of telecommunications systems and wireless devices. Therefore, wireless systems should be expanded [1, 2]. A microstrip monopole antenna is a good candidate for multi-band operations Because it has wide bandwidth impedance, small size, light weight [3-5]. Because wireless local area network (WLAN) and worldwide interoperability for microwave access (WiMAX) technologies are the most widely used in wireless telecommunications devices requires multi-band antenna to fit multiple services in one device. The operating bands for these technologies as assigned by IEEE 802.11 are (WLAN: 2.4-2.484, 5.15-5.35 and 5.725-5.85 GHz) and (WiMAX: 2.5-2.69, 3.4-3.69 and 5.25-5.85 GHz) $[1,3,6-8]$. GSM (900-1800 MHz), CDMA (870$890 \mathrm{MHz})$, PCS (1900 MHz), DCS (1710-1880 MHz), WLAN (2.45/5.8 GHz) and LTE-E/LTE-D (2300$2800 \mathrm{MHz}$ ) [9]. The slots are one of the common processes of miniaturization of antennas while enabling multiband operation, which allow shifting of resonant modes towards lower frequencies [10]. Using the famous printed monopole antenna technology, multi-band resonance antennas have been designed [9]. It is necessary to design ultra-wide antennas with band rejection or multiband characteristics and reconfiguration the ability although many systems do not need to work in all frequency bands [2, 7]. Despite the wide frequency ranges of Ultra Wide Band systems, which give many advantages but cause interference with existing wireless communication systems such as (W LAN) operated at 5-6 GHz and $\mathrm{C}$ band systems in 3.7$4.2 \mathrm{GHz}[3,8]$. In this study, a small microstrip antenna was introduced for multiband applications. The proposed structure includes C-shaped and inverted C-shaped as a basic radiating patch above the substrate layer and rectangular ground plane on the beneath of substrate layer. The bandwidth of the provided antenna is $8.96 \mathrm{GHz}$ at VSWR $<2$. The presented multiband antenna has great return loss and accepted radiation characteristics.

\section{Antenna Design}

The structure provided includes C-shaped and inverted C-shaped patch as a radiant element which is fed by a $50 \Omega$ microstrip line with fixed length $\left(\mathrm{L}_{-} \mathrm{f}\right)$ and width $\left(\mathrm{W}_{-} \mathrm{f}\right)$ and it is printed on the top side of the substrate and a rectangular ground plane with constant (L_gnd) is printed on the other side of substrate as shown in Figure 1, which is designed on FR4 substrate with thickness $1.6 \mathrm{~mm}$ with a dielectric constant (Er) of 4.3. The overall size of the substrate is $\mathrm{X}=14 \mathrm{~mm} \mathrm{X} 24 \mathrm{~mm}$. The antenna provided with different design parameters was simulated and measured results were provided to input impedance and radiation characteristics and to discuss them. All parameters of the multi-band antenna are studied by changing one 
parameter while keeping the other parameters constant. The final dimensions of the proposed antenna are recognized in the Table 1 .

Table-1. Parameters of Proposed Antenna (Units in $\mathrm{mm}$ ).

\begin{tabular}{c|c|c|c|c}
\multicolumn{5}{c}{ Table-1. Parameters of Proposed Antenna (Units in mm). } \\
\hline$W_{\text {sub }}: 14$ & $L_{\text {sub }}: 24$ & $h_{\text {sub }}: 1.6$ & $L_{g n d}: 6$ & $W_{f}: 3$ \\
\hline$L_{f}: 9$ & $W_{1}: 1$ & $L_{1}: 4.5$ & $W_{2}: 0.5$ & $L_{2}: 7$ \\
\hline$W_{a}: 5.7$ & & & & \\
\hline
\end{tabular}

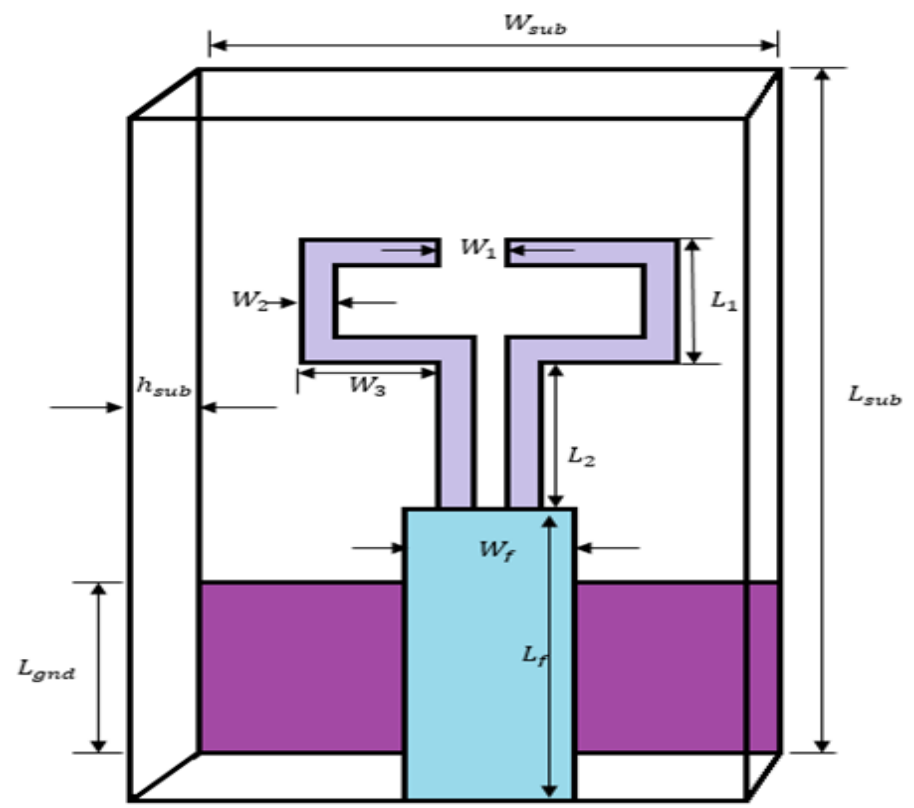

Figure-1. The geometry state of the multiband antenna.

\section{Results and Discussions}

In this paper, different steps of the simulation have been studied to achieve the multi-band antenna structure. Figure 2 shows the four steps of this simulation that were useful to take out the final structure of the proposed antenna. The return loss results for the different antenna steps were simulated in Figure 2 and these results are shown in Figure 3. Figure 3 shows the return loss and resonance frequency for the different steps of proposed antenna. The antenna in the first step gives bandwidth $7.53 \mathrm{GHz}(2.93-10.46) \mathrm{GHz}$. The antenna in the second step gives $0.2 \mathrm{GHz}(2.59-2.74) \mathrm{GHz}$. In the third step, the antenna gives $8.93 \mathrm{GHz}$ $(2.57-11.5) \mathrm{GHz}$. Finally, the antenna in four steps can give $8.97 \mathrm{GHz}(2.56-11.53) \mathrm{GHz}$.

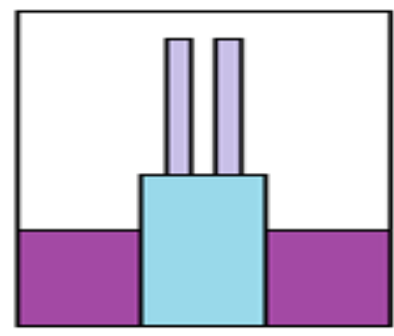

(a)

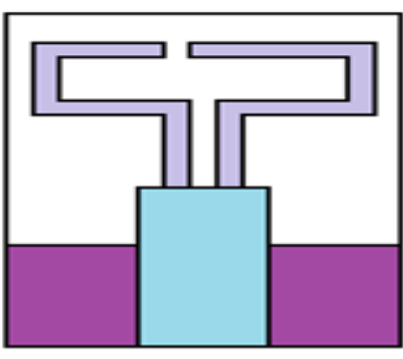

(c)

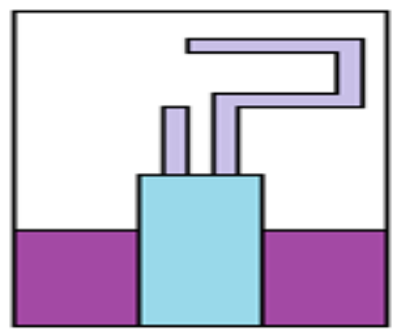

(b)

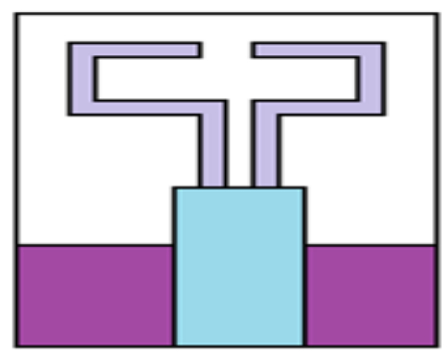

(d)

Figure-2. (a) The antenna in step 1, (b) The antenna in step 2, (c) The antenna in step 3, and (d) The suggested antenna in step 4. 


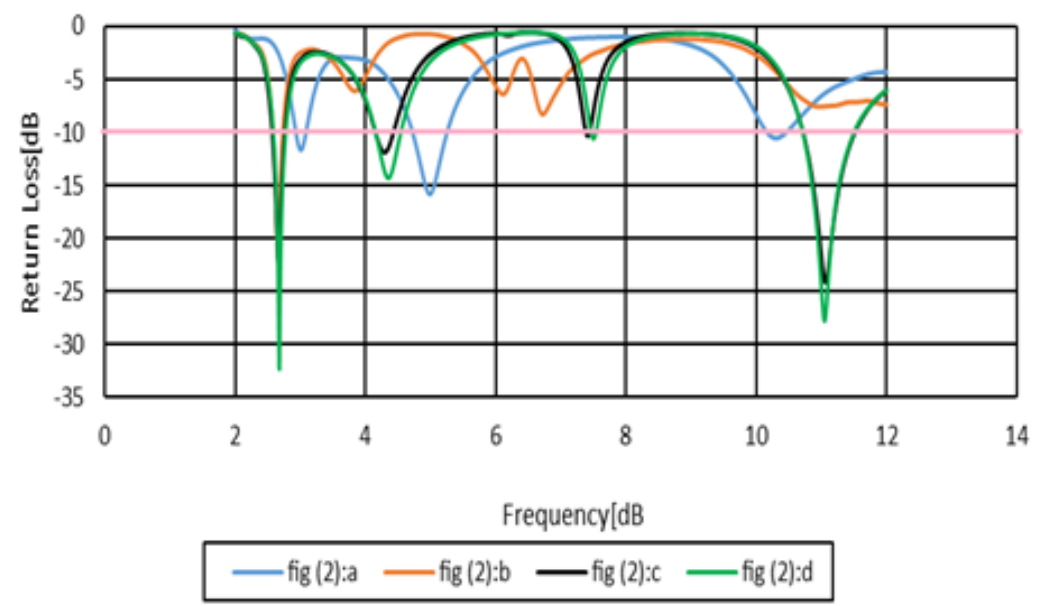

Figure-3. Simulated curves of return loss for antennas in fig 2 (a), (b), (c) and (d).

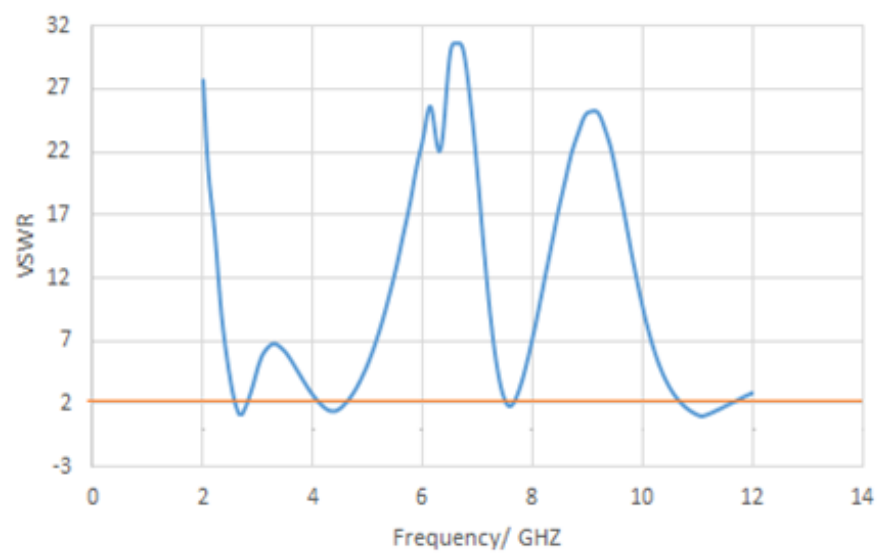

Figure-4. VSWR of the proposed patch antenna.

The VSWR implementation of the monopole antenna is shown in Figure 4, which is between 1 and 2 , for all resonance frequencies with a minimum reflecting capacity of -11 .

The peak gain of the proposed antenna is simulated in Figure 5. The peak gain of the antenna in the first step is $2.72 \mathrm{~dB}$, for the second and third steps the peak gain is 2.73 and $2.7 \mathrm{~dB}$ respectively, Finally, in step 4 the peak gain of the proposed antenna is equal to $2.8 \mathrm{~dB}$.

\section{Gain}

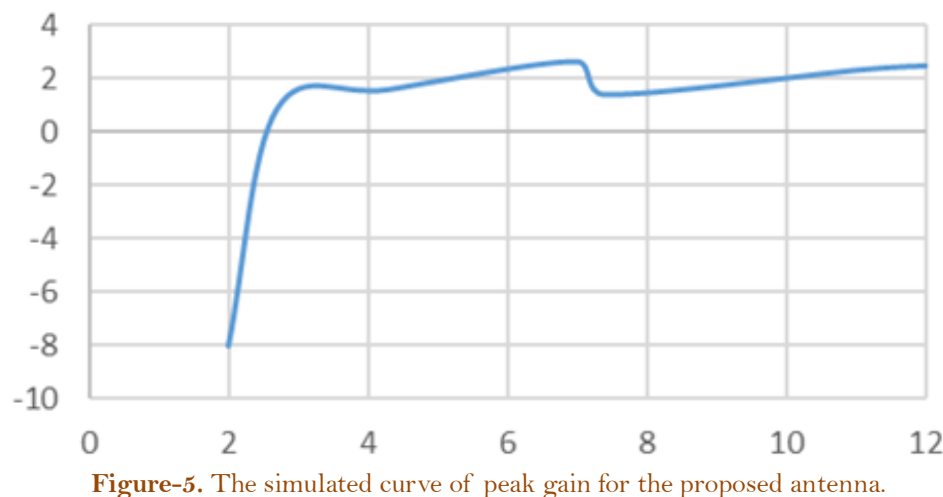

Figure 6 shows the radiation pattern of a microstrip patch antenna, (a) $2.7 \mathrm{GHz}$, (b)4.3 GHz, (c)7.4 GHz, (d) $11.1 \mathrm{GHz}$. The bi-directional radiation pattern of the resonant frequencies Was obtained for the frequencies $2.7 \mathrm{GHz}, 4.3 \mathrm{GHz}$, and $11.1 \mathrm{GHz}$. The directional radiation pattern of the resonance frequencies was obtained at frequency $7.4 \mathrm{GHz}$. 

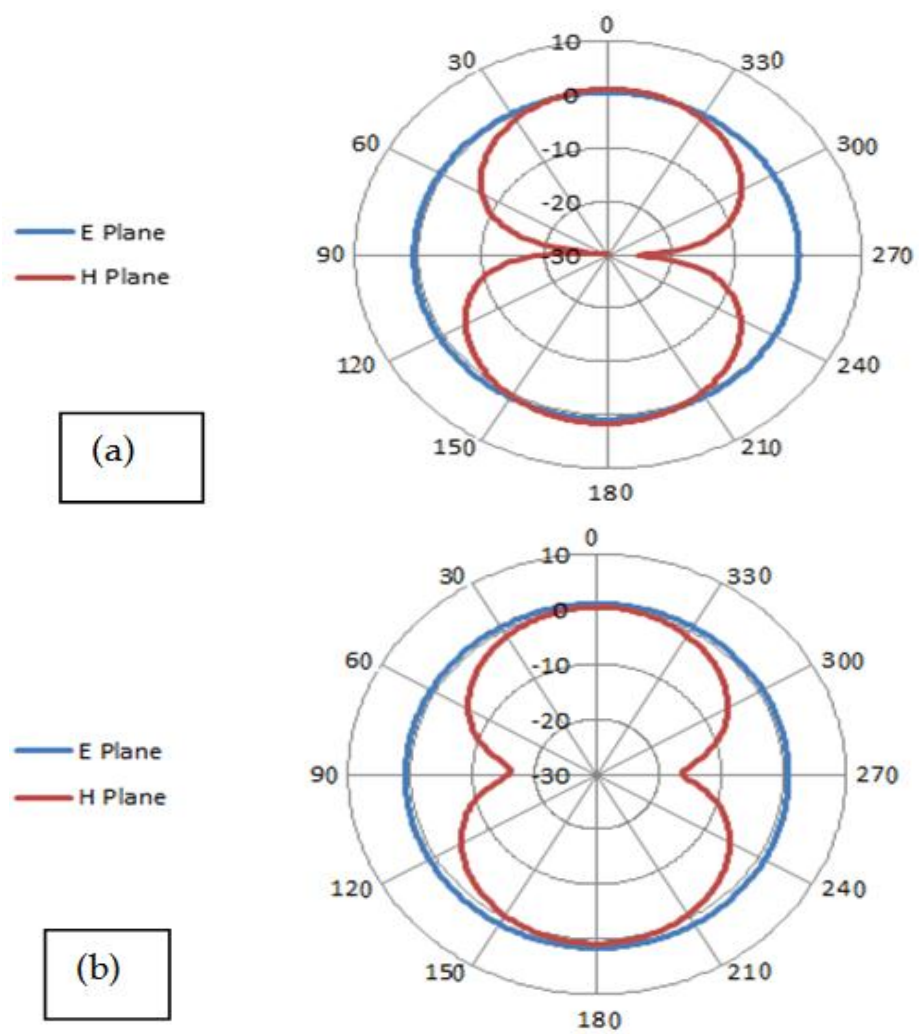

(b)
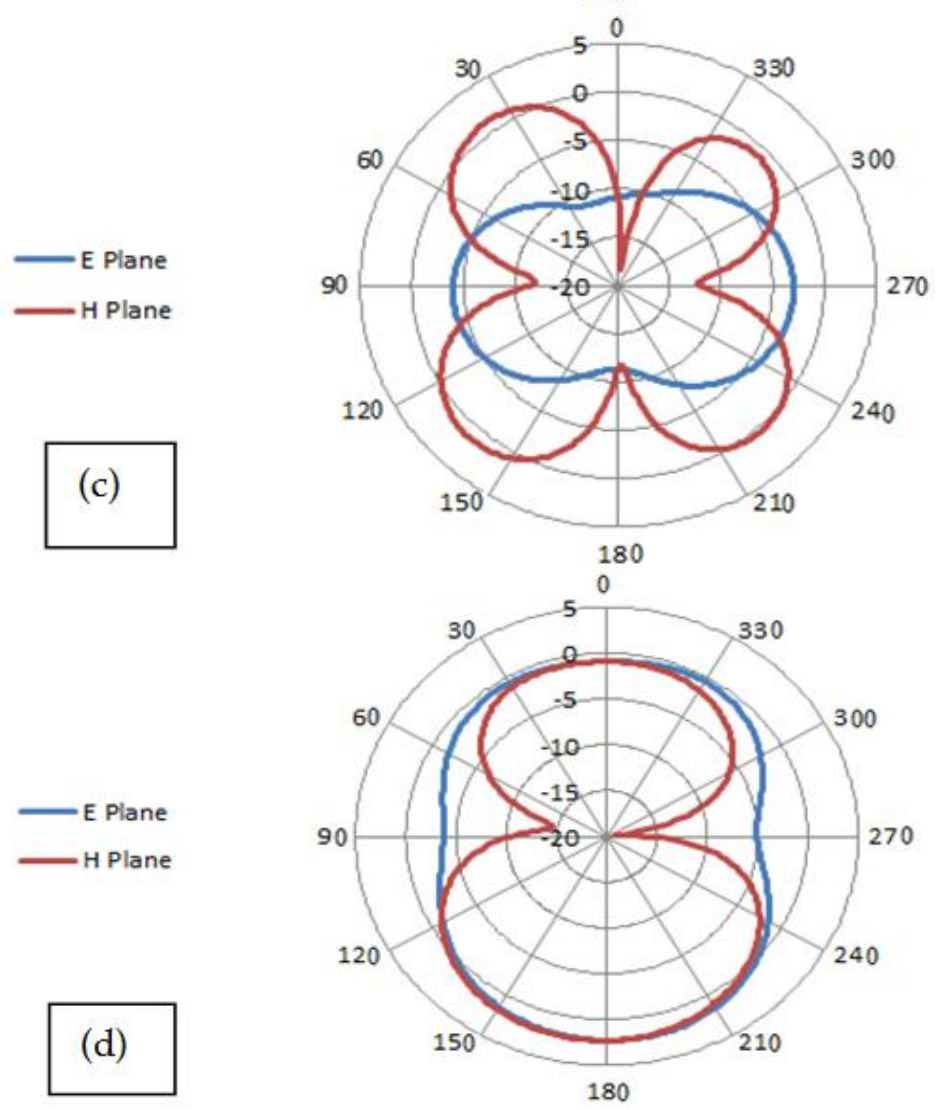

Figure-6. Simulated radiation pattern for the presented antenna at: (a) 2.7 $\mathrm{GHz},(\mathrm{b}) 4.3 \mathrm{GHz},(\mathrm{c}) 7.4 \mathrm{GHz}$ and (d) $11.1 \mathrm{GHz}$. 
Table-2. Comparison the represented antenna with other references.

\begin{tabular}{c|c|c|c|c}
\hline Refs. & Size $\left(\mathrm{mm}^{\mathbf{3}}\right)$ & Bandwidth $\mathbf{G H z}$ & Peak gain dB & $\in_{\gamma}$ \\
\hline$[10]$ & $10 \mathrm{X} 48 \mathrm{X} 1.6$ & 3.4 & 4.09 & 4.3 \\
\hline$[9]$ & $85 \mathrm{X} 125 \mathrm{X} 1.5$ & 5 & 5.82 & 2.2 \\
\hline$[6]$ & $24 \mathrm{X} 35 \mathrm{X} 1.6$ & 4.52 & Not mentioned & 4.4 \\
\hline$[11]$ & $25.7 \mathrm{X} 23.2 \mathrm{X} 1.6$ & 5.8 & 2 & 4.4 \\
\hline$[4]$ & $40 \mathrm{X} 55 \mathrm{X} 2.5$ & 8.28 & 6.76 & 3.5 \\
\hline$[2]$ & $15 \mathrm{X} 25 \mathrm{X} 1.6$ & 6 & 2.47 & 4.4 \\
\hline This Work & $14 \mathrm{X} 24 \mathrm{X} 1.6$ & 8.96 & 2.8 & 4.3
\end{tabular}

\section{Conclusion}

This article proposed the design of a small microstrip antenna for multi-band applications consisting of a radioactive patch $\mathrm{c}$ shape and an inverted $\mathrm{c}$ shape. The multi-band antenna covers the frequency range between $2 \mathrm{GHz}$ and $12 \mathrm{GHz}$ So it provides the best result of WLAN, WiMAX, and C-band applications. Results indicate that the proposed antenna is eligible for multi-band applications.

\section{References}

[1] P. Beigi, J. Nourinia, and Y. Zehforoosh, "Compact CPW-fed spiral-patch monopole antenna with tuneable frequency for multiband applications," JINST 13 PO4014, 2018.

[2] B. Heydarpanah, C. Ghobadi, J. Nouriniaa, and P. Beigi, "A novel printed small antenna with L-shaped structure for multiband applications," JINST 13 P08016, 2018.

[3] P. Beigi and P. Mohammadi, "Bandwidth enhancement of monopole antenna with DGS for SHF and reconfigurable structure for WiMAX, WLAN and C-band applications," JINST 12 T11001, 2016.

[4] N. Prema and A. Kumar, "Design of multiband microstrip patch antenna for C and X band," Optik, vol. 127, pp. 8812-8818, 2016.

[5] R. Anooz, "Bandwidth enhancement by slotted ultrawide band antenna," African Journal of Engineering Research, vol. 7, pp. 10-16, 2019.

[6] A. Kunwar and A. K. Gautam, "Fork-shaped planar antenna for Bluetooth, WLAN, and WiMAX applications," International Journal of Microwave and Wireless Technologies, vol. 9, pp. 859-864, 2017.

[7] P. Beigi and P. Mohammadi, "Bandwidth enhancement of monopole antenna with DGS for SHF and reconfigurable structure for WiMAX, WLAN and C-band applications," JINST 12 T11001, 2017.

[8] D. Yadav, M. P. Abegaonkar, S. K. Koul, V. Tiwari, and D. Bhatnagar, "A compact dual band-notched UWB circular monopole antenna with parasitic resonators," AEÜ - International Journal of Electronics and Communications, vol. 84, pp. 313-320, 2018.

[9] W. T. Sethi, H. Vettikalladi, H. Fathallah, and M. Himdi, "Hexa-band printed monopole antenna for wireless applications," Microw. Opt. Technol, vol. 59, pp. 2816-2822, 2017.

[10] S. S. Al-Bawri, "Multiband slot-loaded dipole antenna for WLAN and LTE-A applications," IET Microw. Antennas, vol. 12, pp. 63-68, 2018.

[11] R. Rajkumar and K. U. Kiran, "A compact metamaterial multiband antenna for WLAN/WiMAX/ ITU band applications," AEU - International Journal of Electronics and Communications, vol. 70, pp. 599-604, 2016. 